\title{
A polissemia do conceito de desenvolvimento no seio da formulação estratégica nacional sobre ciência, tecnologia e inovação
}

\author{
The development concepts within the brazilian nacional science technology and innovation \\ strategy
}

\author{
Cyntia Sandes Oliveira ${ }^{1}$ \\ Magda de Lima Lúcio ${ }^{2}$
}

\begin{abstract}
Resumo
Este artigo objetiva demonstrar como algumas teorias identificadas no seio da formulação da Estratégia Nacional de Ciência, Tecnologia e Inovação (ENCTI) e no Plano Brasil Maior (PBM) abordam o conceito de desenvolvimento, tendo sido observado nos documentos a existência de conceitos distintos, e algumas vezes divergentes entre si, para então compreender como esses conceitos se articulam e estruturam as relações entre Estado, Mercado e Sociedade. Pretende-se, neste artigo, identificar os conceitos, dissecando suas origens e matrizes teóricas, ao mesmo tempo em que se compreende a influência destes na estruturação das políticas públicas em nível estratégico, no que tange ao desenvolvimento nacional. Entende-se que as políticas públicas se realizam na gestão e que os instrumentos por ela engendrados trazem consigo sentidos e significados que, na prática, se traduzem em politização dos processos e dos instrumentos em si mesmos. Percebe-se que o reconhecimento da politicidade interna, intrínseca à escolha dos instrumentos, reflete e permeia os modelos adotados nos processos decisórios governamentais.

Palavras-chave: Estudos do desenvolvimento. Paradigmas. Gestão pública. Ação pública. Brasil.
\end{abstract}

\begin{abstract}
This paper aims to demonstrate how some theories identified within the formulation of the National Science Strategic, Technology and Innovation (ENCTI) and the Plano Brasil Maior (PBM) approach the concept of development. It has been identified the existence of different concepts, sometimes divergent, in the documents. This finding led to the attempt to understand how these concepts are articulated within the relations between State, Market and Society. This paper goal is to identify the concepts, dissecting their origins and theoretical frameworks. Moreover, we intend to understand of their influence on the public policy structure at a strategic level, with respect to national development. It is understood that public policies are structured within management and the instruments it engendered bring along meanings that, in practice, result in the politicization of the processes themselves. It is noticed that the recognition of the inherent political nature, intrinsic to the choice of instruments, reflects and permeates the models adopted in government decisionmaking.
\end{abstract}

Keywords: Development studies. Paradigms. Public management. Public action. Brazil.

1 Doutoranda em Desenvolvimento, Sociedade e Cooperação Internacional (PPGDSCI-CEAM-UnB). E-mail: cyntiasandes@gmail.com

2 Professora Adjunta da Universidade de Brasília (UnB). E-mail: magdadelimalucio@gmail.com 


\section{Introdução}

O presente texto objetiva demonstrar como algumas teorias identificadas no seio da formulação da Estratégia Nacional de Ciência, Tecnologia e Inovação (ENCTI) e do Plano Brasil Maior (PBM) abordam o conceito de desenvolvimento com o objetivo de situar essa discussão para compreender como esses conceitos possibilitam a articulação entre Estado, Mercado e Sociedade. Nosso objeto é o conceito de desenvolvimento e para abordá-lo, analisamos uma das formulações estratégicas do Estado brasileiro, especificamente direcionada à CT\&I, identificando as suas aparições de maneira a delimitar as abordagens teóricas que exercem influência sobre a estruturação de políticas públicas para o país.

Metodologicamente, partimos do entendimento de que "frequentemente, os filósofos acreditam conhecer o objeto conhecendo-lhe o nome, sem terem bem a noção de que um nome traz consigo uma significação que não tem sentido senão num corpo de hábitos" (BACHELARD, 2013, p. 58). Portanto, vislumbramos que o conceito de desenvolvimento está inserido em "corpos de hábitos", ou noções do que ele significa, que variam conforme a abordagem teórica que o constrói. Essas variações partem de noções das relações entre Estado, Mercado e Sociedade que têm recortes paradigmáticos distintos e que implicam em um conceito de desenvolvimento polissêmico.

É nessa articulação entre a construção de teorias científicas e o processo de entendimento de que categorias e conceitos são significados e ressignificados, conforme são utilizados, que supomos que as teorias se servem de relações entre as instituições - Estado, Mercado e Sociedade - de maneira distinta. A partir da análise e dos interesses identificados em instrumentos governamentais voltados para a ciência, tecnologia e inovação, especificamente a Estratégia Nacional de Ciência, Tecnologia e Inovação (ENCTI) e do Plano Brasil Maior (PBM), identificamos os seguintes conceitos de desenvolvimento, inseridos em matrizes teóricas distintas: desenvolvimento como evolução; desenvolvimento como crescimento; desenvolvimento como liberdade; desenvolvimento sob a ótica da economia neoclássica; desenvolvimento dependente; desenvolvimentismo; desenvolvimento social; desenvolvimento institucionalista e desenvolvimento sustentável. Ao apontar os paradigmas e os conceitos a eles associados, objetivamos destacar o fato de que as teorias partem de premissas, trajetórias e especificidades diferenciadas que, portanto, devem conduzir a um produto da ação igualmente diferenciado e referenciado na definição de estratégicas que conformem políticas públicas. 
O presente texto está estruturado em quatro partes principais: a apresentação da metodologia utilizada; a discussão da associação de paradigmas a conceituações do desenvolvimento; a identificação dos conceitos de desenvolvimento na ENCTI e no PBM; e as considerações finais, que reafirmam o achado de pesquisa, na identificação do implícito identificado na formulação estratégica nacional no que tange aos documentos estudados de que há uma polissemia de conceitos de desenvolvimento no planejamento estratégico nacional.

Na parte voltada à "Metodologia", apresentamos o entendimento de conceito utilizado na análise, justificamos as delimitações de escopo, explicamos o tipo de pesquisa e quais instrumentos foram utilizados para a coleta de dados. Em "Paradigmas e conceituações do desenvolvimento", demonstramos como as conceituações e os métodos de análise do conceito de desenvolvimento não evidenciam uma matriz epistemológica específica e apropriam-se de diferentes paradigmas na construção das relações entre as categorias que determinam o conceito de desenvolvimento sendo discutido. Dessa forma, apresentamos os quatro paradigmas identificados na análise dos documentos escolhidos e a eles associamos teorias, que apresentamos brevemente para que as noções a respeito de tais teorias pudessem fundamentar a associação de determinados trechos dos documentos analisados a correntes teóricas específicas. Finalmente, no que diz respeito à discussão trazida na parte "O conceito de desenvolvimento na ENCTI e no PBM", indicamos as teorias identificadas no seio da ENCTI e do PBM a partir da associação de trechos dos documentos a matrizes teóricas distintas.

\section{Metodologia}

Entendemos conceito como "categoria que estabelece um caso geral a partir de um conjunto de casos particulares aparentados por suas características essenciais" (LAVILLE; DIONNE, 1999, p. 91). No caso em tela, o desenvolvimento é construído conceitualmente a partir de ideias comuns essenciais, como as noções de crescimento e qualidade de vida da população, por exemplo, com o objetivo de "exprimir realidades tendo em comum certos tipos de características" (LAVILLE; DIONNE, 1999, p. 91). Destacamos que esses critérios são apropriados de maneira distinta pelas teorias e essas, por sua vez, são capazes de emanar conceitos e categorias, como, por exemplo, as categorias "Estado" e "equilíbrio de mercado", de acordo com diferentes teorias. 
Identificamos a heterogeneidade quando da utilização do conceito de desenvolvimento no recorte empírico escolhido, a ENCTI e o PBM, por meio de uma análise de conteúdo qualitativa de cunho reflexivo. Dessa maneira, identificamos como diferentes correntes paradigmáticas e teorias delas decorrentes absorvem o conceito desenvolvimento, para apontar a polissemia da sua apropriação nos documentos selecionados. A partir da análise de enunciações, proferiu-se uma análise do implícito, do não dito no texto das políticas, o que constitui o principal achado de pesquisa do presente estudo.

Para identificar a heterogeneidade e diversidade da utilização do conceito nos documentos selecionados, utilizamos a estratégia metodológica de elaborar um quadro teórico-analítico (Quadro 1 - Quadro teórico-analítico das abordagens sobre desenvolvimento) que procurou apresentar os principais aportes identificados, para permitir a análise de atores e interesses envolvidos no seu processo de articulação.

Utilizamos a análise de conteúdo (BARDIN, 2011) para realizar a análise temática, a partir do recorte do conteúdo em fragmentos identificados com teorias, tendo-se em conta a frequência dos temas extraídos dos documentos, enquanto dados segmentáveis e comparáveis. Dessa forma, depreendemos diferentes influências teóricas na proposta nacional de desenvolvimento de Ciência, Tecnologia e Inovação e como essas abordam o conceito de desenvolvimento em suas distintas formas.

Segundo Bardin (2011), a diversidade do corpus que define o que se entende por enunciação incorpora não só entrevistas, como também discussões de grupos restritos, comunicações de massa e discursos políticos. Nesse sentido, entendeu-se viável a sua utilização para os instrumentos de planejamento governamental e ação pública, que além de serem discurso político, podem ser identificados com uma comunicação de massa, estando disponível ao cidadão e, ainda, fomentarem a discussão em grupos restritos quando da formulação da política pública. Dessa forma, entende-se que o discurso não é um produto acabado, de maneira que comporta contradições, incoerências e imperfeições.

A análise da enunciação, portanto, apoia-se na ideia de comunicação como processo. Nesse caso, "o objeto e a ambição da análise da enunciação é apreender ao mesmo tempo diversos níveis imbricados" (BARDIN, 2011, p. 221), de maneira que, a partir do recorte do conteúdo em fragmentos identificados com teorias, realizou-se a análise temática, tendo-se em conta a frequência dos temas extraídos dos documentos, como dados segmentáveis e comparáveis. Assim, a teoria de Bardin (2011) permite uma análise quantitaiva, a partir do estudo da frequência do aparecimento de 
certos conteúdos, e qualitativa, a partir do estudo da definição de categorias analíticas implícitas no discurso e que são associadas a formulações teóricas específicas.

Para a estruturação da análise de conteúdo, identificamos uma série de relatórios sobre os avanços dos objetivos e ações do PBM, mas priorizamos a Lei $\mathrm{n}^{\circ} 12.715 / 2012$, que o institui e seu Balanço Executivo 2011-14 na análise da apropriação do conceito de desenvolvimento realizada na terceira parte do presente texto. No caso da ENCTI, utilizamos o documento "Estratégia Nacional de Ciência, Tecnologia e Inovação 2012-2015”.

Evidenciamos alguns pontos de diferença entre as teorias identificadas na análise de conteúdo, sem, entretanto, discuti-las em profundidade. Para analisar as abordagens do conceito de desenvolvimento, foram definidas categorias de análise, conforme descrito na Tabela 1, partindo-se do conceito desenvolvido por Karl Polanyi (2000) de enraizamento (embebdness), segundo o qual, na moderna economia capitalista, a economia encontra-se desenraizada da sociedade de maneira que assumiu papel central nas interações sociais. Além da relação entre as categorias criadas e as ideias de Polanyi (2000, 1977), também é possível afirmar que essas categorias são encontradas nas diferentes teorias e permitem estabelecer uma diferenciação entre os principais elementos que as diferenciam.

TABELA 1 - DEFINIÇÃO DE CATEGORIAS ANALÍTICAS

\begin{tabular}{|c|c|}
\hline Categorias & Definição \\
\hline Contexto & $\begin{array}{l}\text { Trata-se do momento histórico no qual as teorias apontadas tiveram maior influência na produção } \\
\text { intelectual sobre o desenvolvimento. }\end{array}$ \\
\hline Elemento central & $\begin{array}{l}\text { Núcleo com base no qual o desenvolvimento deve ocorrer, sendo subdividido entre Estado, Mercado e } \\
\text { Sociedade. }\end{array}$ \\
\hline $\begin{array}{l}\text { Significado de } \\
\text { desenvolvimento }\end{array}$ & O que é possível inferir como conceito de desenvolvimento para cada uma das teorias listadas. \\
\hline Principal agente & $\begin{array}{l}\text { Considerado elemento fundamental para articulação dos instrumentos que permitem o alcance do } \\
\text { desenvolvimento. }\end{array}$ \\
\hline $\begin{array}{l}\text { Questionamento } \\
\text { central }\end{array}$ & A partir de que questão parte a construção teórica destacada. \\
\hline Argumento principal & Como a teoria responde à questão de pesquisa. \\
\hline Papel do Estado & Em que posição de importância a teoria coloca o Estado no processo de desenvolvimento do país. \\
\hline Papel & Em que posição de importância a teoria coloca a industrialização no processo de desenvolvimento do \\
\hline
\end{tabular}




\begin{tabular}{|l|l|}
\hline Categorias & Definição \\
\hline Industrialização & país. \\
\hline
\end{tabular}

FONTE: Elaboração própria.

Para Kuhn (1998), é possível identificar escolas pré-paradigmáticas nas quais se identificam categorias que podem ser associadas a conceitos no âmbito de paradigmas. O paradigma comporta a possibilidade de abrigar várias teorias, de forma que oferecem um arcabouço mais amplo no âmbito do qual podem eleger-se categorias. Essas categorias permitem, por sua vez, determinar teorias por meio da utilização de uma metodologia. Teorias, portanto, possuem campo de conhecimento definido, possuindo maior especificidade que paradigmas.

Entendemos, por conseguinte, que teorias estão inseridas em um contexto de paradigmas que traçam pontos em comum em suas abordagens, conforme envidenciamos na Figura 1 - Relação entre paradigmas, categorias e conceitos. Por essa razão, optou-se por iniciar a análise das teorias nos paradigmas que as sustentam, vislumbrando que "os paradigmas poderiam determinar a ciência normal sem a intervenção de regras que podem ser descobertas” (Kuhn, 1998, p. 119). Dessa forma, entendemos que elevarmos o debate sob o ponto de vista da análise paradigmática, para então situarmos os conceitos, nos dá um alcance analítico mais abrangente.

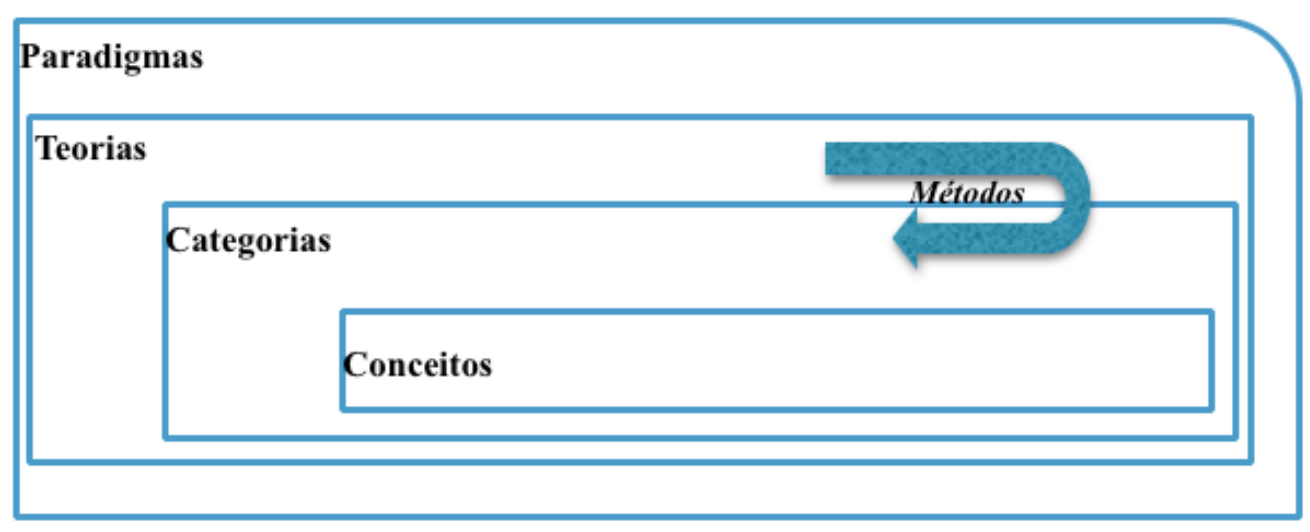

FIGURA 1 - RELAÇÃO ENTRE PARADIGMAS, CATEGORIAS E CONCEITOS. FONTE: Elaboração própria.

Para realizar a análise dos documentos, optou-se pela utilização da ferramenta MAXQDA, software que permite a singularização da quantidade de vezes em que o significante "desenvolvimento" aparece nos documentos selecionados como reporte empírico, bem como a sua associação a significados distintos a partir da análise de segmentos específicos. Dessa maneira, 
utilizou-se o software escolhido para separar trechos da ENCTI e do PBM compatíveis com diferentes correntes teóricas, identificadas no âmbito de paradigmas.

A partir do entendimento evidenciado acima, é possível afirmar que quatro paradigmas principais se destacam quando estudamos as teorias que discutem o conceito desenvolvimento utilizado na ENCTI e no PBM, e conduzem as formulações sobre o tema: o paradigma liberal; o paradigma estruturalista; o paradigma pós-estruturalista; e o paradigma institucionalista. Ao apontar os paradigmas que regem as abordagens do conceito de desenvolvimento, objetivamos destacar o fato de que as teorias partem de premissas, trajetórias e especificidades diferenciadas que, portanto, devem conduzir a um produto da ação igualmente diferenciado e referenciado na definição de estratégias que conformem políticas públicas.

\section{Os paradigmas e as conceituações do desenvolvimento}

Os autores que estudam as teorias do desenvolvimento (SUMMER e TRIBE, 2008; PIETERSE, 2014; VILTARD, 2008; BELLÙ, 2012) apresentam algumas diferenças na forma de conceituar os paradigmas, mas a associação que fazem entre eles e as teorias são similares às utilizadas no presente texto. Summer e Tribe (2008), por exemplo, apresentam três formas de pensar as abordagens a estudos sobre desenvolvimento. A primeira delas, inserida nos paradigmas liberal modernizante e pós-estruturalista, possui um caráter histórico e de longo prazo e se refere ao desenvolvimento como processo de mudança socioeconômica estrutural, incluindo a organização da produção, o nível de apropriação tecnológica e a estrutura institucional vigente. A segunda, que pode ser associada aos paradigmas funcionalista e estrututalista, relaciona-se à escolha de formulações estratégicas, sendo guiada por indicadores que avaliam sua implementação, voltandose a resultados de curto e médio prazos de políticas e programas. A terceira abordagem, associada ao paradigma construtivista, seria pós-moderna, referindo-se à crítica à referência etnocêntrica e carregada de ideologias ocidentais do que é o desenvolvimento, indicando a necessidade de construir concepções alternativas.

As conceituações e os métodos de análise do conceito de desenvolvimento não evidenciam, portanto, uma matriz epistemológica específica; pelo contrário, se utilizam dos grandes paradigmas já reconhecidos e aceitos pelas ciências sociais. Dessa forma, identificamos as formulações teóricas encontradas no documento estratégico, situadas na matriz paradigmática que orienta a conceituação 
do desenvolvimento nas teorias destacadas. Sob essa perspectiva, entendemos que as teorias são derivadas, conforme alguns critérios de análise mais gerais, do entendimento do papel do Estado, do Mercado e da Sociedade.

O controle do sistema econômico pelo mercado é consequência fundamental para a organização da sociedade, de maneira que esta passa a ser dirigida como um acessório do próprio mercado. É nesse sentido que se entende a afirmação de Polanyi (1977), segundo o qual "em vez de a economia estar incrustada nas relações sociais, são as relações sociais que estão incrustadas no sistema econômico" (POLANYI, 2012, p. 77). Então, as relações sociais passam a ser um acessório do mecanismo de equilíbrio de mercado, na medida em que a sociedade, como trabalho, e a natureza, como terra, são inseridos como meios de troca nesse sistema econômico. Segundo Polanyi (1977, p. 10), "a principal questão é que o trabalho e a terra foram transformados em commodities, em outras palavras, foram tratados como se tivessem sido produzidos para a venda" ${ }^{3}$. Esse aspecto influencia boa parte das formulações do conceito de desenvolvimento e está presente em praticamente todas as abordagens do conceito de desenvolvimento dispostas no presente texto.

A partir desse entendimento, estruturamos a tabela de teorias do desenvolvimento, em conexão com os grandes paradigmas que as abrangem. Diante das limitações de espaço relacionadas a um artigo científico, escolhemos algumas teorias identificadas na análise para compor o quadro e, a partir dele, escolhemos teorias para abordar no presente texto, a partir de uma perspectiva em que se busca evidenciar seus principais aspectos, conforme categorias analíticas pré-definidas.

3 No original: the crucial step was that labor and land were made into commodities, that is, they were treated as if they had been produced for sale. 
QUADRO 1 - QUADRO TEÓRICO-ANALÍTICO DAS ABORDAGENS SOBRE DESENVOLVIMENTO

\begin{tabular}{|c|c|c|c|c|c|c|c|c|}
\hline Paradigma & \multicolumn{4}{|c|}{ Liberal } & \multicolumn{2}{|c|}{ Estruturalista } & \multirow{2}{*}{$\begin{array}{c}\text { Pós-estrutu- } \\
\text { ralista }\end{array}$} & \multirow{2}{*}{$\begin{array}{c}\text { Institucio- } \\
\text { nalista } \\
\text { Instituciona- } \\
\text { lismo } \\
\text { Histórico }\end{array}$} \\
\hline Teoria & $\begin{array}{c}\text { Evolucio- } \\
\text { nismo } \\
\text { Social }\end{array}$ & Crescimento & $\begin{array}{l}\text { Desenvolvi- } \\
\text { mento como } \\
\text { Liberdade }\end{array}$ & $\begin{array}{c}\text { Neoclássica } \\
\text { do } \\
\text { Desenvolvim } \\
\text { ento }\end{array}$ & $\begin{array}{c}\text { Dependên- } \\
\text { cia }\end{array}$ & $\begin{array}{c}\text { Desenvolvi- } \\
\text { mentismo }\end{array}$ & & \\
\hline Contexto & $\begin{array}{l}\text { Séc. XIX e } \\
\text { meados do } \\
\text { século XX }\end{array}$ & $\begin{array}{c}\text { Déc. } \\
1890-1930\end{array}$ & $\begin{array}{c}\text { Déc. } \\
1950-60\end{array}$ & $\begin{array}{c}\text { Déc. } \\
\text { 1980-... }\end{array}$ & $\begin{array}{c}\text { Déc. } \\
1940-50\end{array}$ & $\begin{array}{c}\text { Déc. } \\
\text { 1960-70 }\end{array}$ & $\begin{array}{c}\text { Meados da } \\
\text { déc. } 1980\end{array}$ & $\begin{array}{c}\text { Déc. } \\
\text { 1990-... }\end{array}$ \\
\hline $\begin{array}{c}\text { Elemento } \\
\text { central }\end{array}$ & Mercado & Mercado & Mercado & Mercado & Mercado & Mercado & Sociedade & Mercado \\
\hline $\begin{array}{c}\text { Significado } \\
\text { de } \\
\text { desenvolvi- } \\
\text { mento }\end{array}$ & $\begin{array}{c}\text { Cresciment } \\
\text { o } \\
\text { econômico } \\
\text { e } \\
\text { civilização }\end{array}$ & $\begin{array}{c}\text { Crescimento } \\
\text { econômico } \\
\text { exógeno }\end{array}$ & $\begin{array}{c}\text { Ampliação } \\
\text { das } \\
\text { possibilidad } \\
\text { es de } \\
\text { escolha } \\
\text { individuais }\end{array}$ & $\begin{array}{c}\text { Crescimento } \\
\text { econômico - } \\
\text { reformas } \\
\text { estruturais, } \\
\text { desregulação } \\
\text { liberalização, } \\
\text { privatização }\end{array}$ & $\begin{array}{c}\text { Acumula- } \\
\text { ção de } \\
\text { capital ou } \\
\text { crescimento } \\
\text { econômico }\end{array}$ & $\begin{array}{c}\text { Acumula- } \\
\text { ção de } \\
\text { capital ou } \\
\text { crescimento } \\
\text { econômico }\end{array}$ & $\begin{array}{c}\text { Inclui fatores } \\
\text { sociais para } \\
\text { além do } \\
\text { crescimento } \\
\text { econômico. }\end{array}$ & $\begin{array}{c}\text { Expansão das } \\
\text { capacidades } \\
\text { da cidadania; } \\
\text { Crescimento } \\
\text { sustentável e } \\
\text { do PIB. }\end{array}$ \\
\hline $\begin{array}{c}\text { Principal } \\
\text { agente }\end{array}$ & Estado & Estado & Mercado & Mercado & Indivíduo & Estado & Estado & Indivíduo \\
\hline $\begin{array}{l}\text { Questiona- } \\
\text { mento } \\
\text { central }\end{array}$ & $\begin{array}{l}\text { Quais são as } \\
\text { condições } \\
\text { sociais, } \\
\text { políticas e } \\
\text { econômicas } \\
\text { para o } \\
\text { alcance do } \\
\text { desenvolvi- } \\
\text { mento? } \\
\text { Quais } \\
\text { modelos de } \\
\text { crescimento } \\
\text { permitem o } \\
\text { desenvolvi- } \\
\text { mento? }\end{array}$ & $\begin{array}{l}\text { Há causali- } \\
\text { dade entre } \\
\text { equidade e } \\
\text { crescimen- } \\
\text { to? }\end{array}$ & $\begin{array}{c}\text { Definição } \\
\text { dos preços } \\
\text { no mercado, } \\
\text { mecanismo } \\
\text { autorregu- } \\
\text { lado? }\end{array}$ & $\begin{array}{c}\text { Dependên- } \\
\text { cia estrutural } \\
\text { e subdesen- } \\
\text { volvimento, } \\
\text { subprodutos } \\
\text { do } \\
\text { desenvolvim } \\
\text { ento? }\end{array}$ & $\begin{array}{c}\text { Dependên- } \\
\text { cia } \\
\text { estrutural e } \\
\text { subdesenvol } \\
\text { vimento } \\
\text { como um } \\
\text { subproduto } \\
\text { do } \\
\text { desenvolvi- } \\
\text { mento? }\end{array}$ & $\begin{array}{c}\text { Como o } \\
\text { crescimento } \\
\text { afeta a } \\
\text { pobreza? }\end{array}$ & $\begin{array}{c}\text { Que tipos de } \\
\text { capacidades } \\
\text { institucio- } \\
\text { nais são } \\
\text { necessárias } \\
\text { ao Estado na } \\
\text { busca do } \\
\text { desenvol- } \\
\text { vimento? }\end{array}$ & \\
\hline $\begin{array}{c}\text { Argumento } \\
\text { principal }\end{array}$ & $\begin{array}{c}\text { Cresciment } \\
\text { o } \\
\text { econômico }\end{array}$ & $\begin{array}{c}\text { Crescimento } \\
\text { econômico }\end{array}$ & $\begin{array}{c}\text { Liberalismo } \\
\text { baseado em } \\
\text { direitos }\end{array}$ & $\begin{array}{c}\text { Ajuste } \\
\text { estrutural - } \\
\text { livre ação do } \\
\text { mercado }\end{array}$ & $\begin{array}{c}\text { Mudança } \\
\text { estrutural } \\
\text { macroeco- } \\
\text { nômica - } \\
\text { capitais } \\
\text { internacio- } \\
\text { nais }\end{array}$ & $\begin{array}{c}\text { Mudança } \\
\text { estrutural } \\
\text { macroeco- } \\
\text { nômica - } \\
\text { neomarxista }\end{array}$ & $\begin{array}{c}\text { Examinar o } \\
\text { nexo entre } \\
\text { distribuição } \\
\text { de renda e } \\
\text { pobreza, e } \\
\text { entre } \\
\text { equidade e } \\
\text { crescimento }\end{array}$ & $\begin{array}{c}\text { Aprimorar } \\
\text { capacidades } \\
\text { estatais com } \\
\text { o objetivo de } \\
\text { expandir as } \\
\text { capacidades } \\
\text { da cidadania }\end{array}$ \\
\hline $\begin{array}{c}\text { Papel do } \\
\text { Estado }\end{array}$ & $\begin{array}{l}\text { Garantir as } \\
\text { instituições }\end{array}$ & $\begin{array}{l}\text { Garantir as } \\
\text { instituiçõos }\end{array}$ & $\begin{array}{c}\text { Garantir as } \\
\text { instituições } \\
- \\
\text { capacidades } \\
\text { individuais }\end{array}$ & $\begin{array}{l}\text { Garantir as } \\
\text { condições } \\
\text { para a livre } \\
\text { ação do } \\
\text { mercado. }\end{array}$ & $\begin{array}{c}\text { Promover o } \\
\text { bem-estar } \\
\text { social }\end{array}$ & $\begin{array}{c}\text { Promover o } \\
\text { bem-estar } \\
\text { social }\end{array}$ & $\begin{array}{c}\text { Promover o } \\
\text { bem-estar } \\
\text { social }\end{array}$ & $\begin{array}{l}\text { Financiar, } \\
\text { empreender e } \\
\text { atuar no } \\
\text { mercado }\end{array}$ \\
\hline $\begin{array}{c}\text { Papel da } \\
\text { industrializa } \\
\text { ção }\end{array}$ & Central & Central & Irrelevante & Central & Central & Central & Irrelevante & Relevante \\
\hline
\end{tabular}

FONTE: Elaboração própria. 
Nos próximos subtópicos, abordaremos, portanto, a nossa forma de nomear os paradigmas identificados nos documentos estratégicos escolhidos, bem como as teorias a eles associadas. Dessa forma, apresentaremos, em primeiro lugar, o paradigma para, em seguida, expor as principais características das teorias que associamos a ele. Iniciaremos pelo paradigma liberal modernizante, seguindo pela apresentação da Teoria da Modernização, da Teoria do Crescimento e demais teorias a ele associadas, para depois situar os demais paradigmas e as teorias que entendemos como inseridas em cada um deles.

\section{O Paradigma Liberal e as teorias por ele influenciadas}

Sob a égide do paradigma liberal agregamos a Teoria do Crescimento, a Teoria do Desenvolvimento como Liberdade e a Teoria Neoclássica do Desenvolvimento por serem teorias associadas de maneira mais forte com a satisfação do equilíbrio de mercado, necessário ao crescimento, pressuposto base voltado para o desenvolvimento como ferramenta para o progresso. Identificamos, pois, que há explicações sobre essas ideias como liberais e modernizantes por diferentes autores que tratam dos estudos do desenvolvimento na contemporaneidade (ESCOBAR, 1995; PIETERSE, 2010; GÉRONIMI et al., 2008; SUMMER e TRIBE, 2008).

\section{A Teoria da Modernização e a Teoria do Crescimento}

A partir dos pressupostos gerais apontados no paradigma liberal, identificamos elementos na Teoria da Modernização e na Teoria do Crescimento que fazem com que seja possível situá-las no âmbito daquele paradigma. A Teoria da Modernização, associada a estudos antropológicos e sociológicos, apresenta noções relativas a uma ideia de progresso associada ao desenvolvimento das sociedades, que passam de um estado primitivo a um estágio civilizado (EASTERLY, 2001), muito associado à cultura europeia do século XIX.

A Teoria da Modernização é fruto de seu tempo e teve proeminência durante o século XIX, encontrando em autores como Spencer (1863) e Durkheim (1893) alguns de seus principais portavozes. A influência de Spencer dá-se nas Ciências Sociais como um todo ao evidenciar o debate em torno do conceito de evolucionismo que, no caso dos estudos do desenvolvimento, associa-se à ideia de existirem civilizações desenvolvidas e povos não civilizados ou subdesenvolvidos. $\mathrm{O}$ 
trabalho de Durkheim, The Division of Labor in Society, de 1863, exerceu influência e tratou da noção de que as formas de manutenção da ordem na sociedade podem ser prescritas para que sociedades tidas como primitivas façam a transição para sociedades mais avançadas, no sentido de mais desenvolvidas. Esses posicionamentos abrem seus respectivos campos de estudo e buscamos apresentá-los como pensamentos fundacionais, que contextualizam e iniciam os estudos sobre o desenvolvimento dentro do escopo do paradigma liberal.

Diante do direcionamento dado à necessidade de progresso, entendemos a satisfação do equilíbrio de mercado como elemento central de análise dessa abordagem. Assim, desenvolvimento é identificado com crescimento econômico e mudança civilizacional, instituindo modelos que deveriam ser seguidos para o seu alcance. O Estado é considerado o principal agente desse esforço de transformação, na garantia de instituições que dariam suporte à superação do atraso em relação a outras nações. Igualmente, a industrialização apresenta-se como central ao esforço de desenvolvimento.

Ainda sob o arcabouço paradigmático liberal, inserem-se as Teorias do Crescimento (Big Push), trabalhadas no âmbito da economia e desenvolvidas inicialmente no contexto histórico do final do século XIX e início do século XX. Entre seus autores, figuram clássicos da teoria do desenvolvimento, como Solow, Harrod-Domar e Rostow (EASTERLY, 2001). Esses modelos preconizam métodos para se alcançar o desenvolvimento, como crescimento econômico, por meio da industrialização, entendida como fundamental a esse esforço. Segundo esses modelos, o desenvolvimento se daria a partir da alta injeção de capital associada à intervenção, liderada pelo setor público, direcionada à industrialização. Dessa forma, o desenvolvimento econômico resultaria do crescimento da economia nacional.

O elemento central de análise, portanto, é o mercado, que dimensiona os modelos de crescimento com a utilização de base tecnológica exógena. Ao Estado é reservado o papel de garantir os meios para a satisfação das necessidades do equilíbrio de mercado, uma vez que o crescimento é possibilitado pela aquisição dos meios técnicos exógenos que o proporcionam. A maioria desses modelos concebe o alcance do desenvolvimento no longo prazo, desconsiderando elementos locais que interferem no processo, a exemplo das características da sociedade e da classe política. Ainda, os esforços a serem desprendidos para o alcance do estágio de desenvolvimento almejado voltam-se ao consumo de massa e a uma medida estritamente econômica, o Produto Interno Bruto (PIB), variável que fazia sentido no campo da economia e que estava disponível. 


\section{Desenvolvimento como Liberdade}

$\mathrm{Na}$ Teoria do Desenvolvimento como Liberdade, identificamos aspectos que nos levaram a associá-la à economia que, por meio dela, busca inserir o ser humano nas análises, em razão da associação feita entre a capacitação do indivíduo e as possibilidades de aumento da produtividade, a partir das inovações decorrentes dessa realidade. Também encontramos essa abordagem em outras formulações e é possível associá-la às ideias schumpeterianas sobre a destruição criadora que está inserida nos processos de inovação produtiva, porém, no caso da teoria do desenvolvimento como liberdade, a inovação é consequência do fornecimento de capacidades que habilitem a escolha do indivíduo.

$\mathrm{O}$ autor ao qual mais se associam as ideias presentes nessa teoria é Amartya Sen, economista indiano ganhador do prêmio Nobel de economia. Também é possível identificá-las na Teoria da Justiça do filósofo político John Rawls, que tem como principal argumento a reconciliação entre liberdade e equidade nas instituições sociais para que elas possibilitem o atendimento de dois princípios básicos de justiça: o igual direito à liberdade de escolha e a razoabilidade das desigualdades sociais e econômicas de maneira que não inviabilizem o proveito de todos (ABBAGNANO, 2015, p. 685). Sen (2000) apresenta a forma de ver o desenvolvimento a partir da promoção da liberdade individual, que se torna possível com a capacitação dos indivíduos. As capacidades individuais proporcionam o arbítrio e, como tal, a liberdade, mas também contribuem para o desenvolvimento global, que diz respeito a toda a sociedade que se beneficia desse processo.

A teoria de Sen (2000) abrange um liberalismo baseado em direitos, de maneira que se espera do Estado a garantia dos meios que propiciem o desenvolvimento das capacidades individuais, sendo a melhoria das condições de vida da população resultada de esforços dirigidos pelo e para o indivíduo que se qualifica a lidar com as mudanças no seu papel social, conjugando suas ações com os interesses e vantagens conferidos pelo mecanismo de mercado:

Combinar o uso extensivo dos mercados com o desenvolvimento de oportunidades sociais deve ser visto como parte de uma abordagem ainda mais ampla que também enfatiza liberdades de outros tipos (direitos democráticos, garantias de segurança, oportunidades de cooperação etc.). Neste livro, a identificação de diferentes liberdades instrumentais (como intitulamentos econômicos, liberdades democráticas, oportunidades sociais, garantias de transparência e segurança protetora) tem por base o reconhecimento do papel de cada uma, bem como de suas complementaridades (SEN, 2000, p. 152). 
A industrialização, nesse contexto, está inserida dentre as possibilidades da dinâmica da vida econômica, mas não é o seu centro. Em relação ao lugar ocupado pelo Estado, ele é entendido como mecanismo regulatório, que garanta a sustentabilidade dos bens públicos, a liberdade dos indivíduos e o cumprimento das regras do jogo. Essa teoria possui forte associação às ideias liberais de Adam Smith, como o próprio Amartya Sen (2000) destaca em diferentes passagens do seu livro "O Desenvolvimento como Liberdade".

\section{A Teoria Neoclássica do Desenvolvimento (Neoliberalismo)}

A Teoria Neoclássica do Desenvolvimento (Neoliberalismo) foi inserida no quadro teóricoanalítico, pois se identifica que as práticas respaldadas por esta teorização, no que diz respeito aos esforços para o desenvolvimento, ainda que sejam muito questionadas, são reiteradas na contemporaneidade. Identificamos que essa teoria é uma estrutura analítica importante e influi na formulação estratégica nacional.

Para o neoliberalismo, o desenvolvimento significa o alcance do crescimento econômico por meio de reformas estruturais que promovam a desregulação, a liberalização e a privatização, ocasionando a diminuição do papel do Estado e colocando o mercado como o principal agente, uma vez que ele é entendido como mecanismo autoregulado. $\mathrm{O}$ atendimento dos mecanismos de mercado é assim apresentado como elemento central para o desenvolvimento, no sentido de que a própria ideia de desenvolvimento está associada ao crescimento econômico e ao atendimento dos seus imperativos.

Em última instância, a utilização reiterada das políticas preconizadas por essa forma de pensar o desenvolvimento vem sendo associada às causas da crise financeira da segunda metade dos anos 2000, que resulta do processo de financeirização que deslocou os investimentos do aspecto produtivo da economia para o financeiro. Entendemos esse deslocamento como a maximização do "desenraizamento" entre economia e sociedade indicada por Polanyi. Com o neoliberalismo, a economia se distanciou da função de facilitar a articulação entre as relações sociais, como parte mesmo constitutiva da sociedade, e a acumulação virou o fim em si mesmo, deixando de ser o meio. Diante desse quadro, outras formas de pensar o desenvolvimento retomam a reflexão em torno do papel do Estado para forjar o equilíbrio entre as diferentes instâncias da vida social. 


\section{O Paradigma Estruturalista, o Pós-estruturalismo e as teorias por eles influenciadas}

Escolhemos tratar dos dois paradigmas em conjunto porque identificamos que há muitos pontos em comum entre as duas abordagens, de forma que buscamos apontar o que as diferencia, mas articulando a sua análise conjuntamente. $\mathrm{O}$ estruturalismo e o pós-estruturalismo têm em comum a importância conferida ao papel do Estado e de suas instituições na mudança estrutural que conduz ao desenvolvimento. Nesses paradigmas, é possível identificar o tratamento da realidade social como um conjunto formal de relações que estão associadas à estrutura econômica, sob a qual deve atuar o Estado para realizar o tipo de mudança que pode conduzir ao desenvolvimento.

O pós-estruralismo apresenta uma abordagem que se diferencia do estruturalismo no maior enfoque dado ao papel da sociedade como agente de transformação e para quem se dirige o processo que conduz ao desenvolvimento. Essa correlação denota um direcionamento do pósestruturalismo para uma visão calcada na importância central da sociedade para o desenvolvimento, apresentando uma abordagem do conceito como apropriação social, com relevante papel do Estado para a satisfação das necessidades da sociedade, prioritariamente em relação ao mercado.

Ao apresentar o estruturalismo como guarda-chuva teórico para a teoria da dependência e do desenvolvimentismo, enquanto vislumbramos o pós-estruturalismo como paradigma do desenvolvimento social, buscamos dar-lhes destaque como abordagens que convivem e ainda disputam espaço na atualidade, estando muito presentes nas discussões sobre o desenvolvimento latino-americano.

O estruturalismo como paradigma de determinados aportes aos estudos do desenvolvimento deixa clara a importância do Estado como agente responsável pela estruturação de um ambiente favorável ao desenvolvimento. Para essa corrente, é papel do Estado coordenar a inserção internacional dos países em vias de desenvolvimento, de maneira que estes sejam capazes de disputar os espaços de negociação internacionais, que determinam as trocas e as leis que regem o convívio entre os países no sistema internacional.

Segundo os estruturalistas (FURTADO, 1956, 1961, 1974, 2000; PREBISCH, 1949; CARDOSO e FALETTO, 2000), o sistema internacional foi estruturado de forma a perpetuar a vantagem comparativa de inserção internacional dos países desenvolvidos, os quais exercem influência decisiva na definição de fatores que determinam o crescimento e o desenvolvimento nacionais, como as taxas de câmbio, as vantagens nos termos de troca, o domínio sobre patentes e a propriedade intelectual. 
Igualmente, a corrente do estruturalismo apresenta uma análise que direciona o desenvolvimento ao atendimento das necessidades do mercado na medida em que a inserção diferenciada das sociedades dá-se na busca pela industrialização e pelas vantagens comparativas inerentes a países do Sul, tais como a perpetuação de um mercado agrícola voltado à exportação, à produção de commodities e à expansão de indústrias de transformação de baixo valor agregado. Nesse sentido, pode-se argumentar que o estruturalismo traz uma abordagem do conceito de desenvolvimento que pode ser entendida como relacional.

O “não desenvolvido", em relação ao "desenvolvido", criou o conceito de "subdesenvolvimento" utilizado como elemento explicativo da existência de países então considerados "subdesenvolvidos". O questionamento a essa construção teórica, com seus significantes e significados, acarretou principalmente na mudança na forma de nomear os países “não desenvolvidos”, que passaram a ser tratados como países "em desenvolvimento".

A reflexão sobre o relacional na conceituação do desenvolvimento pode conduzir ao questionamento sobre a ideia de desenvolvimento em si (ESCOBAR, 1995), constituindo um indicativo de rompimento paradgmático sobre interpretações da realidade socioeconômica dos países a partir da perspectiva modernizante. Assim, trata-se de uma perspectiva de desenvolvimento que pode não se adaptar às realidades sociais para as quais se destina.

Ainda que se tenha mudado a forma de nomear os países considerados "não desenvolvidos", a relação binária "desenvolvido" e "não desenvolvido" foi apenas amenizada com a utilização de outros termos que ampliam o escopo desse conceito relacional, "país em desenvolvimento" ou "país de menor desenvolvimento relativo". A adoção de outros termos que visam expressar ideias semelhantes ao que se entendia como "subdesenvolvido" mantém o entendimento do conceito de desenvolvimento como relacional. Portanto, permanece o questionamento: "em desenvolvimento" em relação a quê? É sobre esse questionamento que entendemos o desenvolvimento do paradigma estruturalista e da resposta pós-estruturalista. O olhar e questionar a estrutura que estabelece as relações entre Estados e, no seu seio, entre indivíduos, busca no rompimento para com esta estrutura a forma de alcançar o desenvolvimento.

\section{A Teoria da Dependência e o Desenvolvimentismo}

$\mathrm{Na}$ análise das teorias associadas ao paradigma estruturalista, identificamos a Teoria da Dependência e o Desenvolvimentismo como teorias emanadas do campo da economia e trabalhadas em momento histórico no qual é possível identificar a centralidade do Estado. Essa constatação 
evidencia-se na leitura das obras de Furtado (1956, 1961, 1974, 2000) e de clássicos da Comissão Econômica para a América Latina - CEPAL (SINGER, 1953), que marcaram a produção intelectual do período e formularam as bases teóricas da atuação do Estado brasileiro e de estados latinoamericanos na década de 1950 e 1960.

Segundo esses aportes teóricos, o Estado nacional é o principal agente da mudança estrutural necessária para o alcance do desenvolvimento. Para o desenvolvimentismo e para a teoria da dependência, a acumulação de capital e o crescimento econômico são os principais elementos a serem considerados em uma estratégia de desenvolvimento nacional. Além disso, as teorias permitem identificar aspectos estruturais que impedem o crescimento econômico das nações. Para essas teorias, o principal objetivo a atingir para o alcance do desenvolvimento é transformar a base econômica nacional de uma agricultura de subsistência para uma economia cuja dinâmica é ditada pela indústria e pelo setor de serviços. Esse objetivo insere-se diante da teoria da deterioração dos termos de troca dos produtos primários oriundos dos países agrário exportadores, situação típica dos latino-americanos, que se baseava no argumento de que os produtos industrializados beneficiavamse de maiores ganhos derivados do avanço tecnológico, sendo tais ganhos distribuídos aos produtores, sob a forma de renda mais elevada.

A teoria do desenvolvimentismo de Celso Furtado $(1956,1961,1974)$ insiste sobre o componente da desigualdade tecnológica, característica do enfoque dependentista dos anos 1960 e 1970, e que integra as ideologias de implementação do modelo desenvolvimentista no Brasil. A teorização de Furtado (1961) sobre a relação entre desenvolvimento e subdesenvolvimento dá destaque à necessidade de considerar componentes históricos que vão além dos aspectos que influenciam a variação da taxa de crescimento de um país e abordar a questão do desenvolvimentismo a partir de uma matriz econômica historicamente contextualizada e voltada ao aumento da produtividade por meio de inovações tecnológicas.

Para Furtado (1961, p. 177), “o subdesenvolvimento não constitui uma etapa necessária do processo de formação das economias capitalistas modernas. É, em si, um processo particular, resultante da penetração de empresas capitalistas modernas em estruturas arcaicas", de forma que ele vai de encontro à teoria de estagismos de Rostow, conforme expomos ao abordar a Teoria da Modernização e a Teoria do Crescimento. Dessa maneira, o desenvolvimentismo parte de uma análise macroeconômica própria à realidade dos países analisados, em particular, do Brasil.

A tese de Prebisch-Singer sobre a deterioração dos termos de troca ganhou maior escopo na Comissão Econômica para a América Latina (CEPAL). Para essa corrente, os desequilíbrios no 
plano internacional eram consequências das relações desiguais entre centro e periferia do sistema internacional. Essa desigualdade de condições para inserção no mercado internacional era causada pelos termos de troca decrescentes para os países subdesenvolvidos, sujeitos à desvalorização dos produtos agrícolas, commodities, seus principais produtos de exportação. Diante desse contexto, a industrialização possuía um papel central na superação dessa desigualdade, pois, segundo essas teorias, à medida que os países subdesenvolvidos se industrializassem, seus termos de troca melhorariam, deixando de ser decrescentes. Com isso, os países poderiam avançar rumo ao desenvolvimento, por poder competir e se inserir no sistema internacional.

Segundo a tese de Prebisch (1949), como emissores de moedas não conversíveis os países em desenvolvimento possuem menor grau de autonomia política. Dessa forma, desenvolvem-se relações assimétricas entre as nações influenciando na maior vulnerabilidade dos países emergentes às crises financeiras contemporâneas. As assimetrias tecnológico-produtivas reforçam as demais na manutenção da diferença no nível de desenvolvimento dos países, na medida em que monopolizam a inteligência utilizada para seus avanços tecnológicos.

$\mathrm{Na}$ perspectiva sociológica e política, a análise das relações centro/periferia partiu para análises contextualizadoras sobre as relações entre desenvolvimento e subdesenvolvimento. A Teoria da Dependência, desenvolvida, sobretudo, por Cardoso e Faletto (1970), também no interior da CEPAL, emergiu na década de 1970 e suas ideias ainda exercem influência sob a forma de pensar o desenvolvimento latino-americano. Para Cardoso e Faletto, as ideias a respeito do desenvolvimento em voga na década de 1970 (EASTERLY, 2001), que tratavam do desenvolvimento como um processo de estágios dentro dos modelos dos países então considerados desenvolvidos, desconsideravam as características da estrutura social e política latino-americana, pelo qual argumentaram em favor de um procedimento metodológico específico para a realidade latino-americana: "consideramos mais adequado [...] um procedimento metodológico que acentue a análise das condições específicas da situação latino-americana e o tipo de integração social das classes e grupos como condicionantes principais do processo de desenvolvimento" (CARDOSO e FALETTO, 2000, p. 502).

Para a Teoria da Dependência, "entre as economias desenvolvidas e as subdesenvolvidas não existe uma simples diferença de etapa ou de estágio do sistema produtivo, mas também de função ou de posição dentro de uma mesma estrutura econômica internacional de produção e distribuição" (CARDOSO e FALETTO, 2000, p. 507). Dessa maneira, os países desenvolvidos mantêm-se em condição privilegiada em relação às nações subdesenvolvidas dadas as condições próprias à 
estrutura das relações internacionais. Diante desse contexto, os autores diferenciam as noções de dependências das de centro-periferia e desenvolvimento-subdesenvolvimento, pois cada uma delas carrega uma dimensão conceitual distinta e uma diferente implicação teórica.

\begin{abstract}
A noção de dependência alude diretamente às condições de existência e funcionamento do sistema econômico e do sistema político, mostrando a vinculação entre ambos, tanto no que se refere ao plano interno dos países como ao externo. A noção de subdesenvolvimento caracteriza um estado ou grau de diferenciação do sistema produtivo [...] sem acentuar as pautas de controle das decisões de produção e consumo, seja internamente (socialismo, capitalismo etc.) ou externamente (colonialismo, periferia do mercado mundial etc.). As noções de centro e periferia, por seu lado, destacam as funções que cabem às economias subdesenvolvidas no mercado mundial sem levar em conta os fatores políticosociais implicados na situação de dependência (CARDOSO e FALETTO, 2000, p. 508).
\end{abstract}

Para os autores da Teoria da Dependência, o contexto no qual se inserem as relações entre países em desenvolvimento e desenvolvidos deve privilegiar categorias explicativas que sejam historicamente referidas, de maneira que "a especificidade histórica da situação de subdesenvolvimento nasce precisamente da relação entre sociedades 'periféricas' e 'centrais" (CARDOSO e FALETTO, 2000, p. 506).

Ao escrever sobre a estrutura de poder das relações internacionais, Wallerstein (1974) utilizou-se do aporte do paradigma estruturalista, preconizando a análise da macroestrutura internacional, para definir os termos políticos desfavoráveis que caracterizam a inserção internacional dos países da periferia do sistema internacional. As suas contribuições ficaram registradas na categoria que leva o nome de Sistema Mundo e que dispõe sobre a desigualdade estrutural das relações entre os países no contexto sistêmico.

Percebe-se, portanto, que as teorias associadas ao paradigma estruturalista possuem muitos pontos em comum. A sua influência sobre as políticas colocadas em prática no Brasil e na América Latina durante a maior parte do século XX é característica das mudanças estruturais e do processo de inserção internacional dos estados nacionais latino-americanos e, como se evidenciará na análise dos documentos estratégicos selecionados no objeto empírico, ainda exerce influência sobre as formulações estratégicas brasileiras.

\title{
A Teoria do Desenvolvimento Social
}

Ao se tratar de Desenvolvimento Social como abordagem inserida no paradigma pósestruturalista dentro da corrente disciplinar da sociologia do desenvolvimento, identifica-se o 
conceito de desenvolvimento com a inclusão de fatores sociais para além do crescimento econômico como parte das implicações do conceito de desenvolvimento. Assim, seu questionamento central reside no estudo da forma como o crescimento afeta a pobreza, de maneira que seu impacto depende da estrutura inicial de distribuição de renda na sociedade.

Escolhemos a definição de desenvolvimento social descrita por Pieterse (2010) por tratar dessa teoria de forma mais abrangente e por tornar possível indicar as principais características dessa formulação teórica. Dessa maneira, o autor argumenta que "entender o desenvolvimento social de maneira substantiva e abrangente com igual ênfase no 'social' e no 'desenvolvimento': em outras palavras, uma abordagem integral a questões sociais e estratégias de crescimento",4 (localização 2069 de 4109, edição kindle).

Dessa maneira, essa corrente teórica perpassa a necessidade de modificar a estrutura na qual a sociedade encontra-se inserida, sendo influenciada pelo pensamento de Polanyi (1957, 1968, 1977). Diferentemente das teorias abordadas até o momento, esta corrente coloca a sociedade como elemento central de análise, preconizando a diminuição das desigualdades socioeconômicas características do funcionamento do sistema capitalista de mercado. Assim, ela insere a ideia de desenvolvimento do contexto do paradigma pós-estruturalista, contestando as noções tradicionais de desenvolvimento diretamente relacionadas à realidade econômica e insere o conceito em um contexto mais amplo que confere centralidade a questões sociais.

\section{O Paradigma Institucionalista e as teorias por ele influenciadas}

O paradigma institucionalista vem sendo discutido desde a década de 1980 e 1990, passando por um período de reavivamento na contemporaneidade, sendo o mais frequentemente identificado na análise dos documentos estratégicos escolhidos. Para a análise institucionalista, é central o questionamento em torno de como as instituições afetam o comportamento dos indivíduos, pois é pela ação do indivíduo que as instituições afetam o resultado das políticas (HALL; TAYLOR, 1996). Dessa maneira, a centralidade da dinâmica entre instituições e indivíduos conduz o esforço de desenvolvimento de uma nação e é destacada na análise a partir de diferentes perspectivas. Para o institucionalismo histórico, por exemplo, a importância conferida à ação do Estado situa-se no

\footnotetext{
4 No original: "to view social development in a substantive and comprehensive manner with equal emphasis both to the 'social' and 'development': in other words, an integrated approach to social concerns and growth strategies".
} 
fortalecimento do papel do indivíduo como ator central da transformação necessária à maximização de seus benefícios e à satisfação de suas necessidades.

Essa análise incorpora não só o indivíduo como maximizador de utilidade, mas também realizador, de maneira que a decisão sobre o curso da ação individual enfatiza que a escolha sobre o curso de ação pode depender de uma análise situacional, que define os ganhos possíveis em um dado contexto, ou de uma análise de cálculo instrumental, que conduz à ideia de maximizar a utilidade. De uma forma ou de outra, a análise institucionalista coloca o indivíduo no centro das mudanças necessárias ao esforço para o desenvolvimento e as suas variações em escolas de pensamento enfatizam diferentes meios para que o indivíduo possa atuar.

$\mathrm{Na}$ análise institucionalista, prevalecem três escolas de pensamento: o institucionalismo histórico; o institucionalismo da escolha racional; e o institucionalismo sociológico (HALL; TAYLOR, 1996). Esses pensamentos não são homogêneos e no presente texto, priorizamos a perspectiva do institucionalismo histórico, que se sobressai no texto da ENCTI e do PBM, mas entendemos necessário o reconhecimento de outras correntes teóricas sob o paradigma institucionalista. Entendemos que a importância de apresentar o paradigma institucionalista no contexto do presente trabalho está associada à importância conferida ao papel do indivíduo como ator do desenvolvimento no âmbito das escolas de pensamento situadas sob esse paradigma.

É possível afirmar que, para as teorias institucionalistas, o desenvolvimento está associado à expansão das capacidades da cidadania, ao crescimento sustentável e ao crescimento do PIB. Assim, há um aporte da economia e da sociologia nessa corrente teórica na medida em que a referência à sociedade é clara em termos de busca de promover a cidadania e a capacidade de atuação da sociedade, ao mesmo tempo em que a influência da economia é clara nas suas referências ao PIB e ao crescimento sustentável.

Identificamos que a centralidade do indivíduo é recorrente. As instituições devem preconizar o serviço às necessidades do indivíduo. A maneira como os pensadores se apropriam de diferentes conceitos demonstra que a capacitação do indivíduo está voltada ao motivo econômico e, em última instância, à satisfação do equilíbrio de mercado. Dessa maneira, na análise do recorte empírico, identificamos duas teorias que associamos, em maior grau, no caso do institucionalismo histórico e, em menor grau, no caso do desenvolvimento sustentável ${ }^{5}$, às ideias do paradigma institucionalista.

\footnotetext{
5 Ainda que a teoria do desenvolvimento sustentável seja identificada algumas vezes na análise de conteúdo realizada, decidimos suprimi-la do presente texto, dadas limitações de espaço para publicação.
} 


\section{A Teoria do Institucionalismo Histórico}

Ao tratarmos das teorias sob o paradigma institucionalista é possível verificar que o enfoque volta-se às capacidades estatais e à apresentação do Estado como principal ator no esforço em direção ao desenvolvimento. Dessa maneira, segundo Evans (2010), "tanto os teóricos quanto os formuladores de políticas públicas não podem ignorar o papel fundamental das instituições estatais na criação bem-sucedida do desenvolvimento". O autor ainda interpõe que o grande desafio do Estado é repensar o seu papel, pois um número cada vez maior de pesquisadores interpõe que a ideia de expansão das capacidades individuais é importante para a acumulação de capitais visando ao crescimento econômico, bem como para o desenvolvimento de maneira mais ampla (EVANS, 2013). Dessa maneira, a centralidade da atuação das instituições passaria da atuação sobre a acumulação de capitais para o fomento das capacidades individuais.

A principal discussão diz respeito à construção de instituições estatais capazes de conduzir o esforço desenvolvimentista. Mazzucato (2014) discute esse papel ao apresentar o Estado como central ao processo de inovação a partir dos incentivos diretos dados ao setor e dos investimentos passivos em momentos de incerteza para os quais o mercado, por meio da atuação do setor privado, não promove a geração de cadeias de valor consequentes de altos investimentos em ambiente de riscos elevados. Seu livro de 2014, O Estado Empreendedor, fruto de relatório feito para o Reino Unido sobre a importância da atuação estatal na superação de crises, apresenta forte influência keynesiana e schumpeteriana, colocando o papel do Estado em patamar diferenciado, considerando o contexto institucional local.

O Estado é, então, situado como principal agente para o desenvolvimento da capacidade de ação dos indivíduos. Dessa forma, autores como Mazzucato (2014) conferem centralidade à ação estatal sob uma perspectiva neoshumpeteriana de análise, que situa o Estado como facilitador da ação do indivíduo. Nesse sentido, a literatura estudada aborda o fortalecimento das capacidades estatais e o planejamento nacional capazes de conferir ao indivíduo os meios institucionais para a sua ação positiva sobre o desenvolvimento (EVANS, 2010; PETERS, 2000).

A importância conferida às medidas de crescimento pode ser apontada como indício da relevância do equilíbrio de mercado na análise. Nesse contexto, a industrialização é um dos meios para o crescimento econômico, recebendo aportes tecnológicos e investimentos que a capacitem a ser de fato relevante na contagem do PIB e no crescimento sustentável do país. 
Portanto, a respeito do papel conferido à industrialização nas teorias apresentadas, a reflexão de Evans (2012) sintetiza o entendimento do seu papel, especialmente no que diz respeito às abordagens mais recentes do conceito:

A manufatura continua um elemento-chave de qualquer economia em desenvolvimento, assim como a agricultura, porém já não é mais o setor que impele as mudanças nem a principal fonte de emprego ou da expansão do bemestar. A centralidade dos serviços cria um novo conjunto de desafios para o estado desenvolvimentista, forçando-o a se concentrar nas pessoas e em suas habilidades, em vez de máquinas e seus donos. (EVANS, 2012).

Para Nayar (2014, p. 278), “o desenvolvimento é uma questão de criar capacidades de produção nas economias e de assegurar o bem-estar da população dos países”. O autor confere, portanto, maior destaque à industrialização como condição central ao desenvolvimento nacional e explica que há três fatores em comum que a determinam nesse sentido. Para ele, as condições iniciais, as instituições facilitadoras e o papel dos governos como catalisadores ou líderes são fundamentais para a condução do processo voltado ao alcance do desenvolvimento.

A abordagem de Nayar (2014) pode ser relacionada à de Mazzucato (2014) na medida em que ressalta a centralidade do papel do Estado como catalisador de uma estratégia de desenvolvimento que se volta às necessidades do indivíduo. Assim, autores identificados com o institucionalismo histórico destacam o papel que o Estado possui para o desenvolvimento por meio da promoção de um contexto institucional favorável ao desempenho do papel de agente pelos indivíduos.

Segundo Nayar (2014), a articulação entre os três fatores necessários ao desenvolvimento (as condições iniciais, as instituições facilitadoras e o papel dos governos como catalisadores ou líderes do processo) determina a trajetória dos países em relação ao modelo de desenvolvimento adotado. A argumentação em torno da importância do papel do Estado no processo de desenvolvimento pressupõe as falhas de mercado como um fato dado (POLANYI, 2012) e que, portanto, tornam a atuação das instituições fundamental na mitigação dessas falhas. Essas questões fazem das intervenções estatais centrais à condução do processo por meio da integração entre incentivos, capacitação e instituições (NAYAR, 2014, p. 227). 


\section{O conceito de desenvolvimento na ENCTI e PBM}

Com o auxílio do software MAXQDA, formulamos a Tabela 2 - Segmentos e conceitos codificados na ENCTI e no PBM. A tabela evidencia sete teorias sobre o desenvolvimento que permeiam os documentos analisados, atribuindo-lhes cores diferentes e que servem ao propósito de permitir uma análise visual do peso de cada uma delas nos textos. Além disso, a Tabela 2 indica quantos segmentos do texto foram atribuídos às formulações teóricas indicadas na coluna "código", apresentando o percentual que esse número de segmentos representa para a análise dos documentos em conjunto, indicando, por fim, em quantos documentos estratégicos foi possível apontar esses dados. Assim, 73 segmentos textuais foram identificados com a teoria do institucionalismo histórico, representando $28,85 \%$ de peso nos documentos estratégicos estudados e estando presente nos três textos que foram objeto de análise (a ENCTI - Balanço das Atividades Estruturantes; o PBM - Balanço Executivo; e o Decreto 7.540/2011, que instituiu o PBM).

A associação de teorias a segmentos recortados dos documentos buscou identificar em cada um dos trechos destacados elementos que fizessem com que tais trechos pudessem ser associados a uma corrente paradigmática específica, de maneira a relacioná-los com o entendimento que dispomos de cada uma das categorias selecionadas para permitir a análise das teorias. Há casos em que tal associação tornou-se difícil, pois os termos enunciados se encaixam em múltiplas teorizações. Por isso, foi necessário fazer algumas escolhas no que diz respeito a como classificar esses elementos. A polissemia de conceitos nos documentos analisados, indicada na Tabela 2, reforça a polissemia de conceitos de desenvolvimento como ecos de múltiplas teorizações, o que demonstra um arcabouço teórico variado na formulação estratégica estudada sobre ciência, tecnologia e inovação.

TABELA 2 - SEGMENTOS E CONCEITOS CODIFICADOS NA ENCTI E PBM

\begin{tabular}{|ccccc|}
\hline Cor & Código & Segmentos codificados & $\%$ & Documentos \\
\hline$\bullet$ & Desenvolvimento & 37 & 14.62 & 2 \\
\hline - & Tornar-se desenvolvido & 5 & 1.98 & 1 \\
\hline - & Institucionalismo histórico & 73 & 28.85 & 3 \\
\hline$\bullet$ & Neoliberalismo & 24 & 9.49 & 2 \\
\hline$\bullet$ & Desenvolvimento Humano & 17 & 6.72 & 2 \\
\hline$\bullet$ & Desenvolvimentismo & 11 & 4.35 & 2 \\
\hline
\end{tabular}

Guaju, Matinhos, v.2, n.2, p. 26-58, jul./dez. 2016 


\begin{tabular}{|ccccc|}
\hline - Teoria da Dependência & 3 & 1.19 & 1 \\
\hline Desenvolvimento Social & 36 & 14.23 & 2 \\
\hline $\begin{array}{c}\text { Desenvolvimento } \\
\text { Sustentável }\end{array}$ & 45 & 18.58 & 2 \\
\hline
\end{tabular}

FONTE: Elaboração própria.

Para auxiliar o entendimento do que identificamos com as teorias do desenvolvimento na análise dos documentos estratégicos, apontamos as ideias que nortearam a identificação com as teorias na Tabela 3 - Noções presentes nos documentos e identificadas com teorias do desenvolvimento, que resume os aspectos que atribuímos as teorias a trechos específicos da política na determinação da análise dos documentos estratégicos escolhidos.

TABELA 3 - NOÇÕES PRESENTES NOS DOCUMENTOS E IDENTIFICADAS COM TEORIAS DO DESENVOLVIMENTO

\begin{tabular}{|c|c|}
\hline Teoria & Noções \\
\hline $\begin{array}{l}\text { Institucionalismo } \\
\text { histórico }\end{array}$ & $\begin{array}{c}\text { Papel da inovação no desenvolvimento nacional; crescimento do investimento produtivo; } \\
\text { importância das instituições (Estado) na ampliação e criação de regimes especiais para } \\
\text { adensamento produtivo e tecnológico das cadeias de valor; diálogo entre o poder público } \\
\text { e o empresariado. }\end{array}$ \\
\hline Neoliberalismo & $\begin{array}{l}\text { Gerar valor econômico; incorporação de contigente populacional ao mercado de consumo } \\
\text { de massa; ampliar mercados; competitividade. }\end{array}$ \\
\hline $\begin{array}{l}\text { Desenvolvimento } \\
\text { como liberdade }\end{array}$ & $\begin{array}{l}\text { Promoção do desenvolvimento de recursos humanos; fomento aos setores intensivos em } \\
\text { conhecimento. }\end{array}$ \\
\hline Desenvolvimentismo & $\begin{array}{l}\text { Superação de restrições históricas ao desenvolvimento; inserção internacional mais } \\
\text { favorável; fortalecimento da defesa comercial; financiamento e garantia às exportações. }\end{array}$ \\
\hline $\begin{array}{l}\text { Teoria da } \\
\text { Dependência }\end{array}$ & Estágios do desenvolvimento; substituição de importações. \\
\hline $\begin{array}{l}\text { Desenvolvimento } \\
\text { Social }\end{array}$ & $\begin{array}{c}\text { Crescimento afeta a pobreza; distribuição de renda; redução das desigualdades; inclusão } \\
\text { social. }\end{array}$ \\
\hline $\begin{array}{l}\text { Desenvolvimento } \\
\text { Sustentável }\end{array}$ & Economia verde; conservação; uso sustentável da biodiversidade e dos ecossitemas. \\
\hline
\end{tabular}

Dessa forma, na análise dos documentos codificaram-se segmentos, para os quais se atribuiu uma ou mais teorias. Essas associações foram feitas com base no tipo de argumento encontrado em cada uma das teorias e como essas articulam os critérios do que conceituam como desenvolvimento. Assim, por exemplo, quando encontramos segmentos que se referiam ao tipo de atividade econômica buscada como "eficiente e competitiva" os associamos a ideias da teoria neoliberal, que 
comporta esses critérios na sua argumentação. Da mesma forma, fomos associando outros trechos do conteúdo da política a outras teorias ou a mais de uma delas, quando percebíamos que os critérios do conceito de desenvolvimento se sobrepunham para algumas dessas formulações teóricas, a exemplo da ideia de capacitar os indivíduos, que é encontrada nas teorias do Desenvolvimento como Liberdade, no Institucionalismo Histórico e no Desenvolvimento Social.

$\mathrm{Na}$ descrição do enfrentamento aos desafios colocados pelo objetivo disposto pela ENCTI, a polissemia do conceito torna-se ainda mais evidente. Institucionalismo Histórico é associado à redução da defasagem científica e tecnológica e encontra-se junto à ideia de desenvolvimento social, associada à superação da pobreza e redução das desigualdades sociais e regionais, ao mesmo tempo em que são identificados ecos da Teoria da Dependência na descrição da defasagem tecnológica em relação a nações referenciadas como mais desenvolvidas e, finalmente, é feito o reforço da utilização do conceito de desenvolvimento sustentável, então identificado de fato a essa corrente de pensamento, na medida em que coloca como objetivos a ampliação das bases para a sustentabilidade ambiental e desenvolvimento de uma economia de baixo carbono, bem como a expansão e consolidação da liderança brasileira na economia do conhecimento natural.

Ainda nas disposições contidas na ENCTI, é possível identificar o conceito de desenvolvimento humano, frequentemente referenciado no objeto empírico, explicitamente relacionando o atendimento dos objetivos anteriores com a formação e capacitação de recursos humanos. Finalmente, a ENCTI retoma aspectos do Institucionalismo Histórico em diversos momentos e essa referência se evidencia na associação de ciência, tecnologia e inovação - CT\&I a desenvolvimento.

A partir dessa leitura, pode-se afirmar que a ENCTI e o PBM baseiam-se em formulações do conceito de desenvolvimento dissonantes em muitos aspectos, de forma que "o desalinhamento entre os significados e finalidades constituintes do instrumento, suas técnicas e ferramentas impede a realização plena das políticas, uma vez que gera uma contradição interna que acaba por descaracterizar o instrumento e, portanto, o espaço da ação pública” (LUCIO et al., 2014).

Em última instância, a nossa análise demonstra questões que fragmentam os documentos estratégicos internamente no atendimento a objetivos vinculados a diferentes correntes teóricas. Esse exercício não seria válido caso não fossem expostas suas limitações de análise. Na maioria das vezes, é difícil encaixar palavras em teorias específicas, pois, muitas vezes, elas aparecem em maior ou menor medida em mais de uma teoria. Em consequência disso, a distribuição situou as palavras de acordo com a maior ênfase a elas depositadas na teoria alocada. 
A partir da análise dos documentos, concluímos que o Desenvolvimentismo e a Teoria da Dependência, teorizações da década de 1960, permanecem exercendo influência. A ENCTI utilizase textualmente do conceito de "substituição de importações" como premissa de escolhas políticas rumo ao alcance do objetivo de desenvolver o Brasil. Ambas as teorias não apresentam preocupação com o meio ambiente e conferem à industrialização uma importância central para o alcance do desenvolvimento. Por outro lado, a ENCTI e o PBM também evidenciam o Desenvolvimento como Liberdade como base teórica de algumas de suas formulações estratégicas. Para essa teoria, o indivíduo é o centro do esforço para o desenvolvimento e o Estado tem um papel de tornar possível as escolhas individuais.

No caso do paradigma liberal, duas teorias são identificas na ENCTI e no PBM: a Teoria Neoclássica do Desenvolvimento e a do Desenvolvimento como Liberdade. A Teoria Neoclássica do Desenvolvimento traz, de forma prescritiva, a necessidade de primar-se pela eficiência contingencialista, especialmente do Estado, que deveria satisfazer as necessidades do mercado e ser reduzido ao mínimo necessário para a possibilidade da livre ação das forças de mercado. A abordagem do Desenvolvimento como Liberdade também é colocada nesse guarda-chuva analítico, uma vez que o pensamento de Sen (1999) de desenvolvimento de capacidades individuais não se distancia de todo de uma visão de desenvolvimento que está voltada à satisfação das necessidades do mercado e que está centrado no estabelecimento da necessidade de satisfazer as carências de oportunidades dos indivíduos, não se atendo às necessidades que podem emanar da coletividade. Para esse paradigma, o desenvolvimento é funcional a partir do momento em que se atendem às necessidades individuais realizadas no mercado.

Entendemos que é necessário destacar que Sen (1999) possui articulações com outras proposta de desenvolvimento. A sua influência também pode ser percebida no institucionalismo histórico, para o qual o avanço tecnológico possui forte relação com a capacitação dos indivíduos e sua ação como atores no processo de desenvolvimento.

Diante de perspectivas tão diferenciadas no que diz respeito à condução do papel do Estado, aos elementos que devem ter prioridade no esforço para o desenvolvimento e no próprio significado de desenvolvimento, como é possível chegar a formulações estratégicas que efetivamente atendam ao objetivo nacional de tornar-se desenvolvido? Esse questionamento reitera a dificuldade em pensar estrategicamente a partir de uma formulação que evidencia disputas de modelos de futuro.

Identificamos e analisamos indícios de teorias do desenvolvimento no recorte empírico proposto, os documentos estratégicos da ENCTI e do PBM, para então verificar o conteúdo desses 
documentos por meio de técnicas variadas de análise. A nossa análise indicou alguns problemas e desafios para a política de inovação brasileira como instrumento de um projeto de país. O principal deles, inserido na questão de pesquisa que norteou o presente estudo, quanto à verificação de uma polissemia do conceito de desenvolvimento nos documentos estudados, diz respeito à dificuldade que as diferentes noções paradigmáticas que norteiam a formulação estratégica ocasionam.

Como parte dessa dificuldade, o entendimento de que as políticas públicas se concretizam na gestão, no sentido de envolver não apenas instrumentos que sejam técnicos, mas que também reconheçam uma politização interna, refletidos os anseios e perspectivas dos atores envolvidos (LUCIO et al., 2014) também esteve presente na análise da polissemia do conceito de desenvolvimento, identificada nos documentos governamentais selecionados. A relação entre os atores e os sujeitos das políticas implica em quem se beneficia do instrumento escolhido, na escolha da representação do problema e na determinação do comportamento dos atores (LASCOUMES e LE GALÈS, 2004). Implica, dessa maneira, na disputa entre projetos de futuro para o país e seus principais beneficiários. No caso do ENCTI e do PBM, a relação entre atores e sujeitos está conectada à identificação dos conceitos de desenvolvimento eleitos como prioritários para o país. A partir da análise dos documentos escolhidos, identificamos que a estratégica nacional para CT\&I reflete uma dissonância de diretrizes na definição do tipo de desenvolvimento a ser adotado para o Brasil. O estudo dessa dissonância no campo CT\&I coloca questionamentos mais profundos no que diz respeito ao próprio sistema nacional de inovação definido para o Brasil e que será objeto de aprofundamento do presente estudo, a partir de estudos relacionados a essa temática específica.

Dessa maneira, identificaram-se evidências de múltiplas teorias de desenvolvimento nos fragmentos de texto recortados para a análise. Essa identificação corrobora a suposição de que há uma polissemia nos conceitos de desenvolvimento utilizados como base para a formulação dos documentos analisados. Evidencia-se, com isso, uma dificuldade inerente à sua formulação para o alcance dos objetivos colocados pela política.

Por essa razão, pensamos não ser possível apontar a existência de um projeto de desenvolvimento específico para o país, apenas a dissonância que há entre os muitos projetos em jogo. $\mathrm{Na}$ análise conjunta das duas políticas, concluímos que o projeto de desenvolvimento como está posto, colocando ciência, tecnologia e inovação como eixo estruturante, responde a interesses que têm como premissas diferentes aportes teóricos e paradigmáticos. Por um lado, busca atender às necessidades do equilíbrio de mercado no que diz respeito ao aumento da produtividade e competividade brasileiras; por outro lado, levanta questões relativas a um desenvolvimento que não 
seja antagônico às necessidades da sociedade brasileira, trabalhando em prol da inclusão social e que, ao mesmo tempo, considere ainda as questões do desenvolvimento sustentável, respeitando a preservação do meio ambiente.

Conciliar essas questões parece-nos o maior desafio da formulação estratégica ora posta. Nem sempre os objetivos são irreconciliáveis, mas eles têm respondido a paradigmas distintos que trazem diferentes noções em torno do que o futuro representa. Para o paradigma liberal, o futuro dos países em desenvolvimento é seguir as trajetórias trilhadas por países já desenvolvidos, que, por exemplo, não estavam preocupados com a preservação ambiental; para o paradigma estruturalista, a estratégia de desenvolvimento deve ser autóctone e romper com a dependência dos países desenvolvidos, desenvolvendo indústrias e se especializando na produção daquilo que o país apresenta maiores vantagens comparativas; diferentemente, o paradigma pós-estruturalista centra as necessidades do desenvolvimento na sociedade e começa a questionar as ideias relativas à industrialização e perseguir parâmetros voltados ao atendimento das necessidades do mercado. Esses são só alguns exemplos de como as dissonâncias podem ser identificadas e como existem.

\section{Considerações finais}

O presente texto buscou demonstrar como algumas teorias identificadas no seio da formulação da Estratégia Nacional de Ciência, Tecnologia e Inovação (ENCTI) e do Plano Brasil Maior (PBM) abordam o conceito de desenvolvimento com o objetivo de situar essa discussão para compreender como esses conceitos possibilitam a articulação entre Estado, Mercado e Sociedade. Nesse sentido, optou-se por abordar o conceito de desenvolvimento a partir da análise das formulações estratégicas do Estado brasileiro, especificamente direcionadas à CT\&I. Essa abordagem possibilitou a discussão de algumas teorias do desenvolvimento identificadas na formulação estratégica. Para aprofundar a análise de algumas relações identificadas na formulação estratégica, bem como tratar de algumas teorias com mais detalhamento e poder incluir mais teorizações na análise, como no caso do desenvolvimento sustentável, novos estudos devem ser desenvolvidos.

A questão de pesquisa que conduziu a análise realizada no presente texto propôs entender o conceito desenvolvimento e demonstrar como ele se evidencia nos documentos que definem a Estratégia Nacional de Ciência, Tecnologia e Inovação, em articulação com a política industrial, 
tecnológica e de comércio exterior brasileira, instituída com o Plano Brasil Maior (2011-14). Objetivou-se demonstrar como algumas teorias identificadas no seio da formulação da Estratégia Nacional evidenciam uma heterogeneidade na utilização do conceito desenvolvimento e, consequentemente, dissonâncias quando à trajetória para a efetivação de uma política pública que conduza ao desenvolvimento nacional.

A conciliação de objetivos distintos em termos teóricos, na ENCTI e no PBM, demonstra que a articulação entre Estado, Mercado e Sociedade perpassa diferentes matizes teóricas e paradigmáticas no Brasil, o que constitui um dos grandes limites da política, uma vez que se evidenciam projetos de futuro em disputa. Como a definição do próprio conceito de desenvolvimento diz respeito à escolha de projetos de futuro, demonstra-se a importância de instrumentalizar que tipo de desenvolvimento se almeja para o Brasil.

Tal definição do que é desenvolvimento e dos instrumentos de ação pública que lhe venham a ser correspondentes depende do contexto político na qual está inserida (LASCOUMES e LES GALÈS, 2012). Dessa maneira, as evidências empíricas apresentadas demonstram que a ENCTI e o PBM não são instrumentos de ação pública neutros e que, consequentemente, apresentam na sua formulação o aporte de dissonâncias características da política.

Dessa maneira, entende-se que a polissemia de conceitos de desenvolvimento identificada, especialmente na estratégica nacional para CT\&I, reflete uma dissonância de diretrizes na definição do tipo de desenvolvimento a ser adotado para o Brasil, demonstrando, entre as suas consequências, a inviabilidade de executar todos os objetivos propostos, pois os seus pressupostos conduzem a ações públicas diferentes para o alcance do que se está colocando como desenvolvimento. Ponderamos, pois, que os objetivos postos na ENCTI e no PBM atendem a correntes teóricas diferentes e que entendem as causalidades do desenvolvimento de forma dissonante.

\section{Referências}

AGÊNCIA BRASILEIRA DE DESENVOLVIMENTO INDUSTRIAL (ABDI). Balanço Executivo 2011-14 do Plano Brasil Maior. Brasília: ABDI, 2014.

AGÊNCIA SENADO. Promulgada emenda que incentiva ciência, tecnologia e inovação. Disponível em: <http://goo.gl/lgtkBI>. Acesso em: 26 fev. 2015.

ANGELES, L. New issues, new perspectives: implications for international development studies. Canadian Journal of Development Studies, v. XXV, n. 1, 2004. 
ARRIGHI, G. A ilusão do desenvolvimento. Petrópolis: Vozes, 1998.

BALANDIER, G. Les conditions sociologiques du développement. Politique étrangère, n. 3, p. 301-310, 1957.

BANCO MUNDIAL. Knowledge economics: advanced strategies for development. Washington DC: World Bank, 2007.

BARDIN, L. Análise de conteúdo. São Paulo: Edições 70, 2011.

BECKER, H. S. Segredos e truques da escrita. Rio de Janeiro: Zahar, 2015.

BECKER, H. S. Segredos e truques da pesquisa. Rio de Janeiro: Zahar, 2007.

BELLÙ, L. Development and development paradigms: a (reasoned) review of prevailing visions. EASYPol: Resources for policy making Issue Papers. Module 102. Food and Agriculture Organization (FAO), 2012. Disponível em: <www.fao.org/easypol>. Acesso em: 23 jul. 2015.

BUGRA, A.; AGARTAN, K. Reading Karl Polanyi for the twenty-first century: market economy as a political project. New York: Palgrave Macmillan, 2007.

BRASIL. Lei 10.973, de 2 de dezembro de 2004. Dispõe sobre incentivos à inovação e à pesquisa científica e tecnológica no ambiente produtivo e dá outras providências. Diário Oficial [da República Federativa do Brasil], Brasília, DF, 3 dez. 2004. Disponível em: <http://www.planalto.gov.br/ccivil_03/_ato2004-2006/2004/lei/110.973.htm>. Acesso em: 5 nov. 2014.

BRASIL. Lei 5.563, de 11 de outubro de 2005. Regulamenta a Lei 10.973, de 2 de dezembro de 2004, que dispõe sobre incentivos à inovação e à pesquisa científica e tecnológica no ambiente produtivo, e dá outras providências. Diário Oficial [da República Federativa do Brasil], Brasília, DF, 13 dez. 2005. Disponível em: <http://www.planalto.gov.br/ccivil_03/_ato20042006/2005/decreto/d5563.htm>. Acesso em: 2 nov. 2014.

BRASIL. Decreto 7.642, de 13 de dezembro de 2011. Institui o Programa Ciência sem Fronteiras. Diário Oficial [da República Federativa do Brasil], Brasília, DF, 14 dez. 2011. Disponível em: <http://www.planalto.gov.br/ccivil_03/_Ato2011-2014/2011/Decreto/D7642.htm>. Acesso em: 8 nov. 2014.

CHOQUET, C.; DOLLFUS, O.; LEROY, E.; VERNIÈRES, M. (Orgs.) Etat des savoirs sur le développement: trois décennies de sciences sociales en langue française. Paris: Editions Karthala, 1993.

DEMPSEY, N.; BRAMLEY, G.; POWER, S.; BROWN, C. The social dimension of sustainable development: defining urban social sustainability. Sustainable development, 19: 289300, 2011. 
ESCOBAR, A. Discourse and power in development: Michel Foucault and the relevance of his work to the Third World. Alternatives, n. 10, 1985.

ESCOBAR, A. Encountering development: the making and unmaking of the Third World, 2. ed. Nova Jersey: Princeton University Press, 2012.

EVANS, P. Construção do Estado desenvolvimentista do século XXI: possibilidades e armadilhas. In: VIANA, A. L. d’Á.; IBANEZ, N.; Bousquat, A. Saúde, desenvolvimento, ciência, tecnologia e inovação. São Paulo: Hucitec, 2012. Disponível em: < http://goo.gl/ypj5nM>. Acesso em: 15 jul. 2015.

EVANS, P.; HELLER, P. Human development, State transformation and the politics of the developmental State. In: LEIBFRIED, S. et al. (Eds). The Oxford handbook of transformations of the State. Oxford: Oxford University Press, 2013.

FURTADO, C, Desenvolvimento e subdesenvolvimento. Rio de Janeiro: Fundo de Cultura, 1961.

FURTADO, C. Formação Econômica do Brasil. São Paulo: Companhia das Letras, 2006.

FURTADO, C. O mito do desenvolvimento econômico. Rio de Janeiro: Paz e Terra, 1974.

FURTADO, C. Uma economia dependente. Rio de Janeiro: Ministério da Educação e Cultura, 1956.

GABAS, J. J.; RIBIER, V.; VERNIERES, M. La mesure du developpment comment science et politique se conjuguent. Revue Tiers Monde, Paris, Université Paris I, n. 213, jan./mar. 2013.

GERONIMI, V.; BELLIER, I.; GABAS, J. J.; VERNIERES, M.; VILTARD, Y. (Orgs.) Savoirs et politiques de développements. Questions en débat à l'aube du XXIe siècle. Paris: Editions Karthala, 2008.

GOMIDE, A. A.; PIRES, R. R. (Eds.) Capacidades estatais e democracia: arranjos institucionais de políticas públicas. Brasília: Ipea, 2014.

KNUTSSON, B. The intellectual history of development towards a widening potential repertoire. Perspectives, $\quad$ n. 13, apr. $2009 . \quad$ Disponível em: <http://www.gu.se/digitalAssets/1272/1272997_Perspectives_13.pdf>. Acesso em: 15 nov. 2015.

KUHN, Thomas. A estrutura das revoluções científicas. São Paulo: Perspectiva, 1998.

LAVILlE, C.; DIONE, J. A construção do saber - Manual de metodologia da pesquisa em ciências humanas. Porto Alegre: Editora Artes Médicas, 1999.

LASCOUMES, P.; LE GALÈS, P. L'action publique saisie par les instruments. In: LASCOUMES, P.; LE GALÈS, P. (Dirs.). Gouverner par les instruments. Paris: Presses de Sciences Po, 2004.

LASCOUMES, P.; LE GALÈS, P. Sociologie de l'action publique. 2. Ed. Paris: Armand Colin, 2012. 
LUCIO, M. et al. Sentidos e significados de se planejar estrategicamente nas organizações públicas - planejamento estratégico sociotécnico (PLANES): análise de uma experiência. NAU Social, v. 5, n. 9, p. 151-160, nov. 2014/abr. 2015.

MAZZUCATO, Mariana. O Estado empreendedor: desmascarando o mito do setor público versus o setor privado. São Paulo: Portfolio/Penguim, 2014.

MINISTÉRIO DO DESENVOLVIMENTO, INDÚSTRIA E COMÉRCIO (MDIC). Plano Brasil Maior. Disponível em: <http://www.brasilmaior.mdic.gov.br/conteudo/125>. Acesso em: 8 ago. 2014.

MINISTÉRIO DA CIÊNCIA, TECNOLOGIA E INOVAÇÃO (MCTI). Estratégia Nacional de Ciência, Tecnologia e Inovação (ENCTI) 2012-2015. Disponível em: <www.mct.gov.br>. Acesso em: 9 set. 2014.

MINISTÉRIO DO PLANEJAMENTO, ORÇAMENTO E GESTÃO (MPOG). Plano Plurianual 2012-2015: Plano Mais Brasil. Brasília, 2011. Disponível em < http://goo.gl/E1q6rW> . Acesso em: 10 ago. 2014.

MINISTÉRIO DO PLANEJAMENTO, ORÇAMENTO E GESTÃO (MPOG). Secretaria de Planejamento e Investimentos Estratégicos. Plano plurianual 2008-2011: projeto de lei. Brasília: MPOG, 2007.

NAYYAR, D. A corrida pelo crescimento - Países em desenvolvimento na economia mundial. Rio de Janeiro: Contraponto, 2014.

OSTROM, E.; SCHROEDER, L. D.; WYNNE, S. G. Institutional incentives and sustainable development: infrastructure policies in perspective. Boulder: Westview Press, 1993.

PETERS, B. G. Institutional theory: problems and prospects. Viena: Institute of Advanced Studies, 2012. (Political Science Series, 69). Disponível em: <https://www.ihs.ac.at/publications/pol/pw_69.pdf>. Acesso em: 23 jun. 2015.

PEREZ, C. Technological revolutions and techno-economic paradigms. In: Working papers in technology governance and economic dynamics, working paper n. 20. Tallin: Norway and Tallinn University of Technology, 2009.

PIETERSE, J. N. Development theory: deconstructions/reconstructions. 2. ed. Kindle. London: Sage, 2010.

POLANYI, K. A grande transformação: as origens da nossa época. Rio de Janeiro: Elsevier, 2012.

POLANYI, K. A nossa obsoleta mentalidade mercantil. In: DALTON, George (Org.). Primitive, archaic and modern economies: essays of Karl Polanyi. Boston: Beacon Press, 1968. Disponível em: <http://goo.gl/WI4nCi >. Acesso em: 10 jul. 2015. 
POLANYI, K. The economy as an instituted process. In: DALTON, George (Org.). Primitive, archaic and modern economies: essays of Karl Polanyi. Boston: Beacon Press, 1968. Disponível em: 〈http://goo.gl/YDZPYx>. Acesso em: 10 jul. 2015.

SACHS, W. (Ed.). The development dictionary: a guide to knowledge as power. London: Zed, 1992.

SEN, A. Desenvolvimento como liberdade. São Paulo: Companhia das Letras, 2000.

SINGER, H. Obstacles to economic development. Social Research, v. 19, n. 4, p. 19-31, 1953.

SUMMER, A.; TRIBE, M. International development studies: theories and methods in research and practice. London: Sage, 2008.

WALLERSTEIN, I. O fim do mundo como o concebemos: ciência social para o século XXI. Rio de Janeiro: Revan, 2012.

WELZEL, C. Evolution, Empowerment, and Emancipation: How Societies Climb the Freedom Ladder. World Development, v. 64, p. 33-51, 2014.

Artigo recebido em 13/04/2016. Aceito para publicação em 21/07/2016. 